\title{
EL CONCEPTO DE DERECHO DE H.L.A. HART Y LA INDEMNIZACIÓN DEL DAÑO MORAL EN CHILE
}

\author{
THE CONCEPT OF LAW OF H.L.A. HART AND \\ THE COMPENSATION FOR MORAL DAMAGE IN CHILE.
}

\author{
MARÍA CRISTINA GAJARDO HARBOE
}

RESUMEN: En la primera parte del presente trabajo resumiremos los aspectos principales de la teoría que sobre el sistema jurídico propone Hart en su clásica obra "El Concepto de Derecho", a través de los conceptos de aspecto interno y externo de las reglas, de reglas primarias y secundarias, de las reglas de reconocimiento, de cambio y de adjudicación, las técnicas de discrecionalidad y la adecuación del standard variable, la relación entre el derecho y la moral. En la segunda parte explicaremos el sistema de determinación del quantum indemnizatorio del daño moral en Chile, para concluir en la tercera parte y final que no existe una regla de reconocimiento para fijar los montos indemnizatorios del daño moral; se propone un mayor esfuerzo en la fundamentación de las sentencias por parte de los jueces para avanzar en la creación de dicha regla.

Palabras clave: Concepto de Derecho, indemnización, daño moral, determinación del quantum, fundamentación de la sentencia.

ABSTRACT: In the first part of the paper we will summarize the principal aspects of the Hart's theory of the juridical system that proposes in his classic work "The Concept of Law", across the concepts of internal and external aspect of the rules, of primary and secondary rules, of the rules of recognition, of change and of adjudication, the technologies of discretion and the adequacy of the variable standard, the relation between the right and the morality. In the second part of this work, we will explain the system of determination of the quantum of the compensation for moral damage in Chile, to conclude in the third part and end that does not exist a rule of recognition to fix the amounts compensation of the moral damage; one proposes a major effort in the foundation of the judgments on the part of the judges to advance in the creation of the above mentioned rule.

Key words: Concept of Law, indemnification, moral damage, determination of the quantum, foundation of the judgment.

\section{INTRODUCCIÓN}

\subsection{EL CONCEPTO DE DERECHO DE H.L.A. HART}

Para entender un sistema jurídico cualquiera, Hart propone en su obra El Concepto de Derecho un nuevo punto de partida que intentaremos resumir, en lo pertinente a nuestra ponencia.

\footnotetext{
* Abogada, Licenciada en Ciencias Jurídicas y Sociales por la Universidad de Chile. Magíster en Dirección y Planificación Tributaria Universidad Adolfo Ibáñez. Directora Departamento de Derecho del Trabajo y de la Seguridad Social y miembro del Consejo de Facultad. Abogado Integrante de la Corte de Apelaciones de Santiago. Ha publicado diversos artículos en revistas especializadas, expositora en la Escuela Sindical de la Facultad, en diversos seminarios, y ha participado en investigaciones en materias de su especialización. Contacto: mgajardo@derecho.uchile.cl
} 
Distingue entre dos tipos de reglas diferentes, pero relacionadas. Las del primer tipo las llama del tipo básico o primario, prescriben que los seres humanos hagan u omitan ciertas acciones, las quieran o no; estas reglas imponen deberes; se refieren a acciones que implican movimiento o cambios físicos. Las del segundo tipo, que llama secundarias, establecen que los seres humanos pueden, haciendo o diciendo ciertas cosas, introducir nuevas reglas del tipo primario, extinguir o modificar reglas anteriores, o determinar de diversas maneras el efecto de ellas, o controlar su actuación; estas reglas imponen potestades, públicas o privadas; prevén actos que conducen no simplemente a movimiento o cambio físico, sino a la creación o modificación de deberes u obligaciones.

En la combinación de estas dos reglas se halla la clave de la ciencia de la jurisprudencia, esto es, del derecho.

En torno a las reglas secundarias, en cuanto creadoras de deberes u obligaciones, Hart afirma que donde hay normas jurídicas la conducta humana se hace en algún sentido no optativa u obligatoria. Cita a Austin, para quien la obligación dice relación con la probabilidad o riesgo de que la persona que tiene la obligación sufra un castigo o un "mal" a manos de otros en caso de desobediencia, lo que Hart rechaza.

Su objeción fundamental en torno a la interpretación predictiva, es que oscurece el hecho de que, cuando existen reglas, las desviaciones respecto de ellas no son simples fundamentos para la predicción de que sobrevendrán reacciones hostiles o de que un tribunal aplicará sanciones a quienes las transgreden; tales desviaciones son también una razón o justificación para dichas reacciones y sanciones.

Explica que en un sistema jurídico normal en el que se sanciona una elevada proporción de transgresiones, un transgresor corre usualmente el riesgo de sufrir el castigo; el enunciado de que una persona tiene una obligación y el enunciado de que es probable que se lo castigue a causa de la desobediencia, serán ambos verdaderos.

Sin embargo, es crucial para la comprensión de la idea de obligación, advertir que en los casos individuales el enunciado de que una persona tiene una obligación según cierta regla, y la predicción de que probablemente habrá de sufrir un castigo a causa de la desobediencia, pueden no coincidir. Da en este sentido el ejemplo del asaltante, en cuya actuación no hay una obligación implícita pero su víctima se ve obligada a hacer algo.

Distingue las reglas de los meros hábitos sociales y expresa que no siempre es el caso que cuando existen reglas, la conducta requerida por ellas es concebida en términos de obligación; "él debía” y "él tenía la obligación” no son expresiones intercambiables, aun cuando ambas coinciden en comportar una referencia implícita a pautas o criterios de conducta existentes, o son usadas para extraer conclusiones, en casos particulares, a partir de una regla general.

Se dice y se piensa que una regla impone obligaciones cuando la exigencia general en favor de la conformidad es insistente, y la presión social ejercida sobre quienes se desvían o amenazan con hacerlo es grande, aunque no llegue a las sanciones físicas, dependiendo de sentimientos tales como vergüenza, remordimiento y culpa. Cuando la presión es del tipo 
mencionado, podemos sentirnos inclinados a clasificar las reglas como parte de la moral del grupo social y la obligación impuesta por ellas como obligación moral; a la inversa, cuando entre las formas de presión las sanciones físicas ocupan un lugar prominente o son usuales, estaremos inclinados a clasificar las reglas como una forma rudimentaria o primitiva de derecho.

Destaca que la insistencia en la importancia o seriedad de la presión social que se encuentra tras las reglas es el factor primordial que determina que ellas sean concebidas como dando origen a obligaciones.

Estas reglas son reputadas importantes porque se las cree necesarias para la preservación de la vida social o de algún aspecto de ella al que se atribuye gran valor. Además, se reconoce generalmente que la conducta exigida por estas reglas, aunque sea beneficiosa para otros, puede hallarse en conflicto con lo que la persona que tiene el deber desea hacer. De aquí que se piensa que las obligaciones y deberes característicamente implican sacrificio o renuncia, y la constante posibilidad de conflicto entre la obligación o deber y el interés.

La presión social aparece como una cadena que sujeta a aquellos que tienen obligaciones para que no puedan hacer lo que quieren. Pero aclara Hart que la obligación no es algo que consiste esencialmente en algún sentimiento de presión o compulsión experimentado por los obligados, pues está el aspecto interno de las reglas para explicarlo.

Con esta postura del aspecto interno de las reglas desecha las pretensiones de la teoría predictiva. Plantea que el uso característico de las reglas no es el de predecir sino expresar que el caso de una persona cae bajo tal regla.

Distingue entre los aspectos interno y externo de las reglas, lo que permite comprender no solo el derecho sino que la estructura de cualquier sociedad. Por una parte están quienes aceptan las reglas y voluntariamente cooperan en su mantenimiento (aspecto interno), y otros quienes rechazan las reglas y las consideran únicamente desde el punto de vista externo, como signos de un posible castigo.

Hart incorpora la regla de reconocimiento a las reglas primarias, para darles certeza. Esto es muy importante porque es lo que permite identificar un sistema jurídico.

En un sistema jurídico desarrollado las reglas de reconocimiento son más complejas, pues en lugar de identificar las reglas exclusivamente por referencia a un texto o lista, ellas lo hacen por referencia a alguna característica general poseída por las reglas primarias, como el hecho de haber sido sancionadas por un cuerpo específico, o su larga vigencia consuetudinaria, o su relación con las decisiones judiciales. Al contar con una marca o signo de autoridad estas reglas, se introduce la idea de un sistema jurídico. Según veremos en la parte II. nada de esto es claro en el caso del daño moral y su valoración del quantum indemnizatorio en Chile.

Enseguida Hart explica la regla de cambio, como aquella que faculta a un individuo o cuerpo de personas a introducir nuevas reglas primarias para la conducción de la vida del grupo, o de alguna clase de hombres que forman parte de él, y a dejar las reglas anteriores. Están directamente relacionadas con las reglas de reconocimiento. 
Para remediar la insuficiencia de la presión social difusa que ejercen las reglas primarias, están las reglas secundarias, que facultan a determinar, en forma revestida de autoridad, si en una ocasión particular se ha transgredido una regla primaria. Llama a las reglas secundarias que confieren potestad de hacerlas, "reglas de adjudicación", las que además de identificar a los individuos que pueden juzgar, definen también el procedimiento a seguir. No imponen deberes sino que confieren potestades jurisdiccionales a los jueces y acuerdan un estatus especial a las declaraciones judiciales relativas a la transgresión de obligaciones.

Un sistema que tiene reglas de adjudicación está necesariamente comprometido a una regla de reconocimiento de tipo elemental e imperfecto; esto es así porque si los tribunales están facultados para hacer determinaciones revestidas de autoridad sobre el hecho de que una regla ha sido transgredida, no puede evitarse que ellas sean consideradas como determinaciones revestidas de autoridad acerca de cuáles son las reglas.

De esta manera, la regla que confiere jurisdicción es también una regla de reconocimiento que identifica a las reglas primarias a través de las decisiones de los tribunales, y estas decisiones se convierten en una fuente de derecho.

En pocos sistemas jurídicos las potestades judiciales están limitadas a la determinación del hecho de la violación de las reglas primarias. La mayoría de los sistemas han complementado las reglas primarias de obligación mediante reglas secundarias adicionales que especifican, o por lo menos limitan, los castigos por la transgresión de aquellas, y han conferido a los jueces que verifican el hecho de la violación el poder exclusivo de disponer la aplicación de penas por otros funcionarios.

Recapitulando, Hart expresa que la estructura que ha resultado de la combinación de las reglas primarias de obligación con las reglas secundarias de reconocimiento, cambio y adjudicación, es la médula de un sistema jurídico, y también una herramienta muy poderosa para el análisis de mucho de lo que ha desconcertado al jurista como al teórico de la política.

A propósito de la regla de reconocimiento y la validez jurídica, Hart indica que hay dos condiciones necesarias y suficientes para la existencia de un sistema jurídico: por un lado, las reglas de conducta válidas según el criterio de validez último del sistema que tienen que ser generalmente obedecidas, y por el otro, las reglas de reconocimiento que especifican los criterios de validez jurídica, y sus reglas de cambio y adjudicación, que tienen que ser efectivamente aceptadas por sus funcionarios como pautas o modelos públicos y comunes de conducta oficial.

La primera condición, relativa a reglas de conducta válidas, es la única que necesitan satisfacer los ciudadanos particulares: ellos pueden obedecer cada uno "por su cuenta" y por cualquier motivo; si bien en una sociedad saludable las más de las veces se aceptarán realmente estas reglas como pautas o criterios comunes de conducta, y reconocerán la obligación de obedecerles, o incluso harán remontar esta obligación a una más general de respetar la Constitución. 
La segunda condición debe ser satisfecha por los funcionarios del sistema. Ellos tienen que ver en las pautas o criterios comunes de conducta oficial, y apreciar críticamente como fallas las desviaciones propias y las ajenas.

Entonces Hart sostiene que un sistema jurídico es un enunciado bifronte, una de cuyas caras mira a la obediencia por parte de los ciudadanos ordinarios, y la otra a la aceptación de reglas secundarias como pautas o criterios comunes críticos de conducta oficial, por parte de los funcionarios. Esto último no se cumple en Chile en la fijación del quantum indemnizatorio del daño moral.

Otro concepto que Hart introduce en su teoría es el de la textura abierta del derecho. Sostiene que el derecho tiene que referirse en forma predominante, aunque no exclusiva, a clases de personas y a clases de actos, cosas y circunstancias; y su funcionamiento eficaz sobre vastas áreas de la vida social depende de que haya una capacidad ampliamente difundida para ver en los actos, cosas y circunstancias particulares, ejemplos de las clasificaciones generales que el derecho efectúa.

Agrega que por mucho que los criterios y clasificaciones generales operen sin dificultades respecto de la gran masa de casos ordinarios, en algún punto en que su aplicación se cuestione las pautas resultarán ser indeterminadas; tendrán lo que llama una textura abierta. La falta de certeza de las normas en la zona marginal es el precio que hay que pagar por el uso de términos clasificatorios generales en cualquier forma de comunicación relativa a cuestiones de hecho. No podríamos considerar como deseable, ni aun como un ideal, la concepción de una regla tan detallada que la cuestión sobre si ella se aplica o no a un caso particular estuviera siempre resuelta de antemano y nunca exigiera, en el momento de aplicación efectiva, una nueva elección entre alternativas abiertas. Es una característica de la condición humana que en todos los casos que tratamos de regular, en forma no ambigua y por adelantado, alguna esfera de conducta por medio de criterios o pautas generales, para ser utilizados sin nuevas directivas oficiales en ocasiones particulares, nuestro empeño halla dos obstáculos conectados entre sí: el primero es nuestra relativa ignorancia de los hechos y el segundo nuestra relativa indeterminación de los propósitos.

No somos dioses, los legisladores humanos no pueden tener tal conocimiento de todas las posibles combinaciones de circunstancias que el futuro puede deparar.

Entonces, Hart dice que todos los sistemas, de maneras diferentes, concilian dos necesidades sociales: por un lado, la necesidad de ciertas reglas que, en relación con grandes áreas de conducta pueden ser aplicadas con seguridad por los particulares a sí mismos, sin nueva guía oficial o sin necesidad de sopesar cuestiones sociales, y por otro lado, la necesidad de dejar abiertas para su solución ulterior, mediante una elección oficial informada, cuestiones que sólo pueden ser adecuadamente apreciadas y resueltas cuando se presentan en un caso concreto. Ejemplo de esto último es el caso del quantum indemnizatorio del daño moral en Chile.

Pero puede ocurrir que en algunos sistemas jurídicos, en ciertos períodos, se sacrifique demasiado en aras de la certeza, y que la interpretación judicial de las leyes y de los precedentes sea demasiado formal y no se haga cargo de semejanzas y diferencias entre los casos, que sólo 
son visibles cuando estos se examinan a la luz de los objetivos sociales. En otros sistemas, o en otros períodos, puede parecer que los tribunales tratan demasiadas cosas en los precedentes como perpetuamente abiertas o revisables, y que respetan muy pocos límites tales como los que establece el lenguaje de la ley, no obstante su textura abierta.

Para estos efectos, Hart propone dos técnicas, la de la discrecionalidad y la de la adecuación de un estándar variable. Esta última conduce al concepto del precedente jurisdiccional, al que Hart dedica variadas consideraciones.

En cuanto a la discrecionalidad, en el trabajo "Discretion" de Hart aparecen elementos fundamentales, referidos a que no se trata de que cada juez haga lo que se le ocurra al momento de juzgar los casos de penumbra; Hart la entiende como una virtud; destaca la importancia de la institucionalidad en la creación del derecho.

Respecto de los casos difíciles, esto es, aquellas cuestiones no contempladas previamente en las reglas más fundamentales, la aceptación de la autoridad de estas decisiones se obtiene después, en la medida que el juez que se arrogó facultades tenga éxito con su decisión, que sea aceptada.

Por último, en lo que toca a la influencia de la moral sobre el derecho, Hart sostiene que el derecho de todo Estado moderno muestra en mil puntos la influencia tanto de la moral social aceptada como de ideales morales más amplios. Estas influencias penetran en el derecho ya abruptamente y en forma ostensible por vía legislativa, ya en forma silenciosa y de a poco a través del proceso judicial. Ningún positivista podría negar que estos son hechos, sostiene, o que la estabilidad de los sistemas jurídicos depende en parte de tales tipos de concordancia con la moral. Concluye el punto señalando: "Si es esto lo que se quiere decir al hablar de la conexión necesaria del derecho y la moral, su existencia debe ser concedida."

\section{EL DAÑO MORAL Y LA CUANTIFICACIÓN DE LOS MONTOS INDEMNIZATORIOS EN CHILE.}

\subsection{DESCRIPCIÓN DEL MARCO NORMATIVO DEL DAÑO MORAL}

En Chile el daño moral como partida indemnizable civilmente, es un instituto de creación dogmática y jurisprudencial, hecha a partir de los artículos 1556 y 2329 del Código Civil.

De acuerdo al artículo 1556, referido a la responsabilidad civil contractual, "La indemnización de perjuicios comprende el daño emergente y lucro cesante, ya provengan de no haberse cumplido la obligación, o de haberse cumplido imperfectamente, o de haberse retardado el cumplimiento", precepto en que se entiende comprendido el daño moral dentro de los perjuicios indemnizables.

A su turno, el artículo 2329 citado preceptúa que "Por regla general todo daño que pueda imputarse a malicia o negligencia de otra persona, debe ser reparado por ésta", cuya 
generalidad también se entiende que incluye la reparación del daño moral en el ámbito de la responsabilidad extracontractual.

Como se observa, en ninguno de los preceptos legales anotados se explicita el daño moral como partida indemnizable.

La primera sentencia que contempló el daño moral en Chile se dictó el año 1907 por la Corte Suprema ${ }^{1}$, en donde describía dicho daño como "los sentimientos y el valor de afección" y recién el año 1922 la misma Corte Suprema lo reconoció definitivamente 2 .

$\mathrm{Al}$ no existir normas positivas que regulen el daño moral, nuestros tribunales de justicia han esbozado diversos criterios, generalmente de bastante amplitud, entendiéndolo como "la lesión efectuada culpable o dolosamente a un derecho subjetivo de carácter inmaterial e inherente a la persona e imputable a otra", contenido en la sentencia de fecha 7 de agosto de 2008 de la Corte Suprema (Gaceta Jurídica No338, p. 154) o bien como "cualquier menoscabo a un bien no patrimonial", concepto contenido en la sentencia de la Corte de Apelaciones de Antofagasta (Rol 279-2009).

Si bien nuestro sistema obedece a la tradición jurídica continental, en que el precedente jurisdiccional no es vinculante, podemos afirmar que existe una línea jurisprudencial clara y reiterada, contenida en los fallos de los tribunales de justicia, en torno a la procedencia del daño moral en la responsabilidad civil, tanto contractual como extracontractual. Hay una regla de reconocimiento en este ámbito.

\section{FALTA DE UNIFORMIDAD EN LOS MONTOS ASIGNADOS PARA EL DAÑO MORAL}

En Chile no existen reglas que entreguen pautas o mecanismos para valorar el daño moral, una vez que éste se ha acreditado (los tribunales entienden que es preciso acreditarlo, no resultando posible presumirlo). En la fijación de los montos indemnizables se aprecian grandes diferencias de criterios para fijar el quantum indemnizatorio, en casos con similares características. Se ha observado que un factor de relevancia es el geográfico, pues en la zona norte se conceden montos mayores que en la zona sur, y que cuando se trata de víctimas por rebote, los montos suelen también ser mayores si se trata de menores de edad, pero aun así no existen similitudes de montos en casos parecidos.

El criterio de justificación más utilizado para estos efectos por los tribunales chilenos ha sido la discrecionalidad del juzgador, expresada en las sentencias a través de expresiones tales como "arbitrio del juzgador", "apreciación en conciencia", "congruencia", "lo más equitativo y razonable", "razones de justicia", "prudencia”, etc.

El problema de la cuantificación del daño moral no es exclusivo de nuestro país. En modelos comparados se observan esfuerzos de los operadores jurídicos en torno a diseñar herramientas que contribuyan a su uniformidad y certeza.

\footnotetext{
${ }^{1}$ DOMÍNGUEZ HIDALGO (2000) p. 33.

${ }^{2}$ BARROS BOURIE (2006) p. 24.
} 
En Argentina por ejemplo, tratándose de lesiones derivadas de accidentes del trabajo y enfermedades profesionales, existe un tarifado establecido con anterioridad al hecho causante del daño, que facilita la labor de los jueces. España cuenta con un baremo vinculante de responsabilidad civil en la Ley de Ordenación y Supervisión de los Seguros Privados, de 1995, que contiene un anexo sobre "Sistema para la valoración de los daños y perjuicios causados a las personas en accidentes de circulación", que es utilizado como referencia por los tribunales más allá de los accidentes de tránsito.

Este es un enorme problema, no solo de dimensiones prácticas sino también en el ámbito de las garantías fundamentales, porque al no ser posible advertir o anticipar los montos que por daño moral un juez "está pensando" conceder, ni las justificaciones que dará - si es que las da - el responsable de dicho daño no tiene acceso al derecho a defensa en plenitud.

Sostenemos sobre estas bases que en Chile no existen reglas que formen parte del sistema jurídico, relativas a los montos que se conceden a título de indemnización del daño moral. En otras palabras, no hay derecho en este punto.

\section{SOBRE LA FUNDAMENTACIÓN DE LAS SENTENCIAS EN EL DAÑO MORAL}

A la falta de conceptualización del daño moral desde el sistema jurídico positivo suplida por la regla de reconocimiento anotada - y la falta de herramientas dentro del mismo contexto que permitan cuantificarlo de una manera objetiva o al menos con unos mismos criterios para casos similares, se suman enormes deficiencias en la fundamentación de las sentencias al momento de conceder indemnizaciones por este concepto. No se encuentran explicaciones claras de los jueces sobre los motivos que los llevaron a condenar de la manera que lo han hecho.

Esto no debiera suceder, puesto que el mandato del debido proceso consagrado como garantía fundamental en el artículo 19 N³ de la Constitución Política de la República, establece en su inciso sexto que "Toda sentencia de un órgano que ejerza jurisdicción debe fundarse en un proceso previo legalmente tramitado. Corresponderá al legislador establecer siempre las garantías de un procedimiento y una investigación racionales único y justos.”

Este mandato constitucional, en lo referido a la forma de las sentencias, se manifiesta de la siguiente manera en las normas positivas:

- En materia civil: el artículo 170 N4 del Código de Procedimiento Civil establece como un requisito de la sentencia el de contener "Las consideraciones de hecho o de derecho que sirven de fundamento...".

- En materia penal: el artículo 342 literal d) del Código Procesal Penal en los requisitos de la sentencia en un proceso penal exige que contenga "Las razones legales o doctrinales que sirvieren para calificar jurídicamente cada uno de los hechos y sus circunstancias y para fundar el fallo".

- En materia laboral: el artículo 459 N5 del Código del Trabajo exige como contenido de la sentencia "Los preceptos constitucionales, legales o los contenidos en tratados internacionales 
ratificados por Chile y que se encuentren vigentes, las consideraciones jurídicas y los principios de derecho o de equidad en que el fallo se funda."

Así, el sistema jurídico chileno exige ofrecer sentencias fundamentadas cuando se trata de acciones indemnizatorias de perjuicios por daño moral y ello no es así.

En asuntos en que se discute la procedencia de daño moral puro, es decir, no vinculado con lesiones físicas, ha sido inevitable la irrupción de consideraciones genéricas asociadas con la discrecionalidad del juzgador, puesto en la obligación de resolver aun cuando no hay normas que le señalen el camino. Nos parece que la inexistencia de normas legales no libera al juez de la obligación de fundamentar su sentencia.

Un ejemplo claro de lo que exponemos es la sentencia pronunciada con fecha 28 de enero de 2015 por el Juzgado de Letras del Trabajo de San Bernardo, en la causa RIT T-67-2014, en cuyo considerando décimo noveno se lee la siguiente motivación para fijar el monto del daño moral a conceder:

"Que así las cosas y entendiendo esta sentenciadora que en lo que respecta al daño moral, si bien el artículo 486 no habla de indemnización alguna y el artículo 489 del Código del Trabajo establece una indemnización adicional a las propias del despido, en este último caso ésta dice relación con la sola circunstancia de la vulneración de derechos fundamentales, no se requiere en este caso acreditar el daño moral, sólo basta la vulneración de algún derecho fundamental para que el Tribunal pueda otorgarla, de modo que la misma no resulta incompatible con una indemnización por daño moral, pues esta dice relación con la sensación de perjuicio que tenga el trabajador atendidas sus propias característica personales. En razón de lo anterior, se estimó por esta juez que el Tribunal es competente también para pronunciarse respecto al daño moral sufrido por el actor, aun cuando la vulneración se haya producido estando vigente la relación laboral. En el caso particular, se ha acreditado el daño psíquico, el demandante ha sufrido afección emocional con motivo de la agresión sufrida que ha sido tratada durante al menos 6 meses, pues ha requerido de tratamiento psicológico, psiquiátrico y terapéutico ocupacional, de modo que se le otorgará una indemnización por daño moral equivalente a 6 remuneraciones mensuales, considerando una remuneración mensual del actor ascendente a $\$ 461.083$, suma no controvertida por las partes.

En este razonamiento el juzgador en primer lugar presume el daño moral, asumiendo que ante la sola vulneración de una garantía fundamental se origina, obviando por esta vía la línea que viene sosteniendo nuestra Excma. Corte Suprema en orden a la necesidad de acreditarlo ${ }^{3}$. Enseguida, lo hace consistir en "la sensación de perjuicio que tenga el trabajador" cargando el razonamiento de gran subjetividad y sin entregar otras explicaciones para otorgar una indemnización por este rubro demandado.

\footnotetext{
${ }^{3}$ V.gr. sentencia de 20 de enero de 2012, pronunciada en causa "Alvaro Sepúlveda Sanhueza con Empresa Constructora Tecsa”, Rol 4806-2009, Corte Suprema.
} 


\subsection{EN CUANTO A LA EXISTENCIA DE DERECHO EN LA FIJACIÓN DEL MONTO DEL DAÑO MORAL}

A partir de las lecturas de El Concepto de Derecho de Hart, pareciera que en el plano de las reglas secundarias, el derecho es aquello que los jueces crean al resolver un caso concreto, vale decir, la jurisprudencia.

Cuando en el sistema jurídico chileno no existen reglas, cualesquiera que sea su origen (legales, consuetudinarias, emanadas del precedente) para determinar el monto del daño moral, entonces cabe preguntarse si la decisión del juez constituye derecho cuando se basa en la "discreción".

Si aplicamos en términos estrictos el Concepto de Derecho de Hart - y no el camino iniciado en su obra Discretion - tendríamos que concluir que las decisiones de nuestros jueces en estos casos no constituyen derecho, al no dar lugar a reglas de reconocimiento identificables. En efecto, nuestra Excma. Corte Suprema no tiene líneas observables de modo claro en casos parecidos; no hay una larga vigencia consuetudinaria de criterios; menos existe una relación de ellos con las decisiones judiciales.

¿Cómo explicamos entonces que estos fallos sean respetados y cumplidos por los ciudadanos? Sólo podríamos atender a la autoridad de que está revestida la decisión judicial, lo que no parece suficiente para validarla. Quizás esto dé cuenta del poco desarrollo de nuestro sistema jurídico.

\subsection{ACERCA DE LA FALTA DE FUNDAMENTACIÓN DE LAS SENTENCIAS}

Hart no vislumbra ninguna razón aceptable para sostener que la jurisprudencia y la teoría jurídica deban presentarse bajo una forma moralmente justificativa ${ }^{4}$, lo que no impide que la decisión se adopte en base a valores morales sustantivos, es una característica más de un sistema jurídico.

Sin embargo, en la determinación del quantum indemnizatorio del daño moral en Chile es imposible predecir el monto que el juez fijará en un caso concreto, dado que ello lo hará basado en consideraciones completamente subjetivas y personalísimas (lo prudente, lo razonable, lo justo, su “discreción”), las que, además, no suelen venir justificadas o explicadas en las sentencias.

Nuestra propuesta va en torno a la necesidad de explicar, describir, detallar, el proceso de nuestros jueces cuando fijan el quantum del daño moral puro basándose en estas

\footnotetext{
${ }^{4}$ DE PARAMO (2001) pp. 346.
} 
consideraciones morales. Discrecionalidad no significa absoluta libertad, sin controles del sistema, para decidir los casos que se someten al conocimiento de los jueces.

El sistema jurídico chileno debe avanzar hacia una regla de reconocimiento del daño moral y la fijación del quantum indemnizatorio en Chile, para lo cual se precisan fundamentaciones suficientes en las sentencias, por exigirlo así la garantía fundamental del debido proceso, pero por sobre todo, para asegurar la accesibilidad del derecho a todos los ciudadanos y para limitar el poder del Estado, sujetando la función judicial a reglas que puedan ser reconocibles. ${ }^{5}$

\footnotetext{
${ }^{5}$ Sobre la fundamentación de las sentencias a lo largo de la historia, véase "La fundamentación de las sentencias: ¿un rasgo distintivo de la judicatura moderna?”, de Daniela Accatino Scagliotti, disponible en: http://www.scielo.cl/pdf/revider/v19n2/art01.pdf
} 


\section{BIBLIOGRAFÍA}

DOMÍNGUEZ HIDALGO, Carmen (2000): El Daño Moral. Tomo II (Santiago, Editorial Jurídica de Chile, primera edición).

BARROS BOURIE, Enrique (2006): Tratado de Responsabilidad Extracontractual. (Santiago, Editorial Jurídica de Chile).

DE PARAMO, Juan Ramón (2001): Entrevista a H.L.A. Hart. (Alicante, Biblioteca Virtual Miguel de Cervantes)

ACCATINO SCAGLIOT'TI, Daniela (2006): Sobre la fundamentación de las sentencias a lo largo de la historia, véase "La fundamentación de las sentencias: ¿un rasgo distintivo de la judicatura moderna?” Disponible en: http://www.scielo.cl/pdf/revider/v19n2/art01.pdf

\section{JURISPRUDENCIA JUDICIAL}

Alvaro Sepúlveda Sanbueza con Empresa Constructora Tecsa (2009): Corte Suprema, sentencia de 20 de enero de 2012, Rol 4806-2009. 